\title{
Presença, identidade e reputação: estratégias de comunicação das empresas blumenauenses nas redes sociais digitais
}

\section{Presence, identity, and reputation: communication strategies in digital social networks of companies from Blumenau}

Presencia, identidad y reputación: estrategias de comunicación de las empresas de la ciudad de Blumenau en las redes sociales digitales

\section{Fabrícia Durieux Zucco}

- $\quad$ Docente do Departamento de Comunicação da Universidade Regional de Blumenau (Furb) e do Programa de Mestrado e Doutorado em Turismo da Universidade do Vale do Itajaí (Univali).

- $\quad$ Possui graduação em Comunicação Social - Publicidade e Propaganda, especialização em Gerenciamento de Marketing e mestrado em Administração pela Furb.

- $\quad$ Doutora em Administração pela Universidade Nove de Julho (Uninove).

- $\quad$ Tem experiência nas áreas de Administração (com ênfase em Marketing), Turismo e Comunicação.

- E-mail: fabricia@furb.br

\section{Rafael Jose Bona}

- $\quad$ Docente da Universidade Regional de Blumenau (Furb) e da Universidade do Vale do Itajaí (Univali).

- $\quad$ Doutor em Comunicação e Linguagens (UTP)

- Mestre em Educação pela Furb

- $\quad$ Graduado em Comunicação Social - Publicidade e Propaganda pela Furb

- $\quad$ Integrante dos grupos Monitor de Mídia (Univali/CNPq) e Comunicação Midiática (Furb/CNPq).

- $\quad$ Atua em pesquisas sobre intertextos de mídia e consumo com estudos direcionados para o audiovisual, quadrinhos e publicidade.

E-mail: bona.professor@gmail.com

\section{Marina Testoni}

- $\quad$ Pesquisadora graduada em Publicidade e Propaganda pela Universidade Regional de Blumenau (FURB)

- $\quad$ Atuou como publicitária no setor de Atendimento da Agência Seven, de Blumenau

- $\quad$ Participou do Centro Acadêmico Livre de Comunicação (Calco/Furb) e realizou atividades direcionadas para a área da Publicidade e Propaganda

- $\quad$ Colaboradora do grupo de pesquisa Estudos Midiáticos Regionais (Furb/CNPq) com experiência em estudos sobre consumo publicitário e as redes sociais digitais.

- E-mail: marina.testoni@gmail.com 


\section{Resumo}

A finalidade deste trabalho é analisar as estratégias de uso das redes sociais digitais nas empresas de Blumenau/SC a partir da teoria dos Blocos de Construções Funcionais. Para cumprir o objetivo, utilizou-se uma pesquisa qualitativa em sete empresas da região de Blumenau, selecionadas a partir da técnica de amostragem "não probabilística intencional". Como resultado, evidenciou-se que, embora as empresas estejam inseridas nas plataformas das redes sociais digitais, elas ainda não possuem o conhecimento necessário para se adequarem a esse meio.

PALAVRAS-CHAVE: ESTRATÉGIAS DE COMUNICAÇÃO • REDES SOCIAIS DIGITAIS • EMPRESAS • BLOCOS DE CONSTRUÇÕES FUNCIONAIS • BLUMENAU.

\section{Abstract}

This work's purpose is the analysis of the strategies of digital social networks use in Blumenau/SC, from the theory of Functional Building Blocks. To fulfil this objective, we used a qualitative research in seven Blumenau regional companies, selected from "intentional non-probability" sampling technique. As a result we noticed that, although they are inserted in digital social networks, they still do not have the necessary knowledge to suit this kind of media.

KEYWORDS: COMMUNICATION STRATEGIES • DIGITAL SOCIAL NETWORKS • COMPANIES • FUNCTIONAL BUILDING BLOCKS • BLUMENAU.

\section{Resumen}

La finalidad de este trabajo es analizar las estrategias de uso de las redes sociales digitales en las empresas de Blumenau/SC a partir de la teoría de los Bloques de Construcciones Funcionales. Para cumplir el objetivo, se utilizó una investigación cualitativa en siete empresas de la región de Blumenau, seleccionadas a partir de la técnica "no probabilística intencional". Como resultado, se evidenció que, aunque las empresas están insertas en las plataformas de las redes sociales digitales, todavía no poseen el conocimiento necesario para adecuarse a ese medio.

PALABRAS CLAVE: ESTRATEGIAS DE COMUNICACIÓN•REDES SOCIALES DIGITALES • EMPRESAS• BLOQUES DE CONSTRUCCIONES FUNCIONALES• BLUMENAU. 
A internet reformulou a maneira de distribuição das mensagens comunicacionais, o modo de consumo de produtos, bem como o relacionamento dos consumidores com as organizações (Dimitriadis; Tsimonis, 2014). 0 ambiente digital pode ser considerado um elemento-chave no planejamento da comunicação integrada de marketing e não um mero substituto da mídia convencional (Okazaki; Taylor, 2013). Prova disso é a maneira como os atores sociais estão cada vez mais compartilhando informações entre si (Wang; Kim, 2017) devido às facilidades providas pela cultura da convergência midiática (Jenkins, 2016), o que tem se tornado importante para todas as organizações.

De acordo com uma pesquisa realizada pelo Instituto Brasileiro de Opinião Pública e Estatística (Ibope, 2016), os brasileiros dedicam, diariamente, mais tempo à web do que a qualquer outro meio de comunicação - em média, são quase cinco horas por dia. Os sites mais acessados são as redes sociais digitais, que acabam sendo um portal de informações diárias.

O relatório sobre o Brasil publicado no GlobalWeblndex (2016) também aponta que as redes sociais digitais são as mais acessadas pelos brasileiros (52\%), o que ratifica a importância dessas plataformas como fonte de informação - as quais se tornaram parte integrante do cotidiano de muitos atores sociais. Zhu e Chen (2015) apontam que tais plataformas proporcionam novas oportunidades e desafios para as empresas.

0 relacionamento empresa/consumidor consiste em não apenas emitir informações, mas também saber escutar e ser de utilidade para esse consumidor. As redes sociais digitais permitem ampliação, facilitação e aceleração do diálogo entre empresa e seus potenciais clientes, de maneira impossível de ser obtida em outros meios (Yanaze, 2011). 0 cenário é reiterado por Silva, Alves e Oliveira (2016) ao constatarem como as redes sociais digitais são importantes para impulsionar vendas e negócios das empresas por meio da interação com os atores sociais. Isso se deve ao ambiente mercadológico que tem se tornado cada vez mais competitivo.

Nesse contexto, as redes sociais digitais afetam o relacionamento não somente entre os atores sociais, mas também entre as organizações e os consumidores. Devido ao grande número de usuários, essas redes representam uma ferramenta de publicidade atraente para as organizações (Dimitriadis; Tsimonis, 2014).

As plataformas de mídia social digital permitem, de maneira interativa, ampliar, facilitar e acelerar o diálogo da empresa com seus potenciais clientes, o que dificilmente pode ser alcançado com outros meios de comunicação. Tudo o que antes era desenvolvido por meio de anúncios e ações promocionais, atualmente é realizado por meio de uma relação individualizada e personalizada com o objetivo de fidelizar, aproximar e despertar o interesse do consumidor (Mendonça, 2013; Silva; Alves; Oliveira, 2016; Yanaze, 2011).

Nos últimos dez anos, pesquisas de diversos autores, como as de Limeira (2007); Kaplan e Haenlein (2010); Barefoot e Szabo (2010); Kietzmann et al. (2011); Yanaze (2011); Hanna, Rohm e Crittenden (2011); Jue, Marr e Kassotakis (2010); Castronovo e Huang (2012); Mendonça (2013); Zhu e Chen (2015); Pinhanez (2015); Sousa (2016); Camara (2016); Silva, Alves e Oliveira (2016); e Wang e Kim (2017), evidenciam a importância da utilização da comunicação digital como estratégia de marketing das empresas e apontam as redes sociais digitais como viabilizadoras de oportunidades de negócio e de vantagens competitivas.

Este estudo analisa as estratégias do uso das plataformas das redes sociais digitais das empresas de Blumenau/SC, a partir da teoria dos Blocos de Construções Funcionais. Dedica-se a aprofundar, regionalmente, a temática e compreender esse cenário nas empresas. Como referencial teórico-metodológico, utilizou-se um recorte do modelo desenvolvido por Kietzmann et al. (2011), que definiram o uso estratégico das plataformas de mídia social em sete blocos de construções funcionais: Identidade, Conversas, Compartilhamento, Presença, Relacionamento, Reputação e Grupos. 
Esta pesquisa foi desenvolvida no âmbito de grandes empresas de Blumenau, município do sul do Brasil, localizado no estado de Santa Catarina. Trata-se da terceira cidade mais populosa do estado e um de seus principais polos industriais e tecnológicos. 0 município está em quarto lugar dentre as maiores economias de Santa Catarina e possui uma forte influência no estado. De acordo com o IBGE (2016), a população estimada é de 338.876 habitantes.

\section{MARCO TEÓRICO}

As redes sociais digitais, na última década, têm transformado o papel dos atores sociais por estes se tornarem ávidos nas trocas de dados e participarem ativamente na criação e no compartilhamento de informações (Wang; Kim, 2017). Os grandes meios de comunicação estão conectados por uma rede cada vez mais complexa e, na atualidade, "tornou-se muito mais difícil fazer distinções clássicas entre comunicações interpessoais, organizacionais e de massa", pois todo o conteúdo disponibilizado na rede mundial de computadores flui com um simples toque de um mouse (Jenkins, 2016, p. 216).

A comunicação deixou de ser somente um conjunto de ações para transmitir uma mensagem e passou a ser um conjunto de plataformas de trocas de informações e de construção de relacionamentos. A internet amadureceu e trouxe inovações importantes que reforçam o caráter relacional da comunicação digital; com isso, passa a ocupar a terceira posição entre os veículos de comunicação de maior alcance e fica atrás, apenas, da televisão e do rádio. Outrossim, a internet possui alta confiabilidade e é fortemente consultada para decisões de compra (Yanaze, 2011). De acordo com os dados oriundos da pesquisa realizada pelo lbope (2016), é possível ratificar que a internet continua sendo um dos meios de comunicação mais utilizados pelos brasileiros.

A partir de seus estudos, Mangold e Faulds (2009) observam alguns métodos que os gestores podem utilizar para moldar as discussões dos consumidores na mídia social. Esses procedimentos incluem as plataformas de rede, ferramentas de mídia social e ferramentas promocionais e todos visam o envolvimento dos clientes. Nesse contexto, Yanaze (2011) acrescenta que as organizações podem ser ativas nas plataformas de relacionamento, oferecer promoções e ficar à disposição para atender seus consumidores.

É fato que as redes sociais digitais auxiliam na comunicação entre a empresa e o usuário, porém, algumas vezes, as propagandas na mídia social não são bem vistas, uma vez que os usuários se conectam a esses meios para conversarem e trocarem informações entre eles e as empresas se conectam para realizar o seu marketing e venderem seus produtos. Os atores sociais acostumaram-se a ver anúncios nos meios tradicionais de propaganda, como em televisão e jornais, mas no meio digital isso ainda pode causar certo desconforto e ser mal interpretado, o que prejudica as empresas (Zhu; Chen, 2015).

O notório poder exercido pela mídia social, com seu ônus e bônus, ainda não impactou uma grande parte das empresas que relutam ou são incapazes de desenvolver estratégias e recursos para aproveitarem, efetivamente, suas ferramentas. Consequentemente, as empresas ignoram regularmente ou desperdiçam as oportunidades e ideias apresentadas pelos consumidores (Kietzmann et al., 2011).

As ferramentas da mídia social podem afetar, significativamente, o potencial de vendas de uma empresa, bem como a sua sobrevivência. Todavia, muitos gestores evitam ou até mesmo ignoram a utilização das diferentes plataformas de mídia, seja pela falta de conhecimento de como manipulá-las ou pelo desconhecimento dos variados formatos que podem apresentar. Ao pensar nesse entrave, Kietzmann et al. (2011) estudaram um quadro que define, com a utilização de sete blocos de construções funcionais, as diferentes plataformas de mídia social. 
Esses blocos foram estudados para auxiliar os gestores no entendimento das diferentes atividades que as plataformas de mídia social podem assumir, e são divididos em: Identidade, Conversas, Compartilhamento, Presença, Relacionamento, Reputação e Grupos. Cada bloco fornece sugestões de como as empresas podem se envolver de maneira efetiva nessas plataformas. Outrossim, ao levar em conta o poder que a mídia social fornece para a comunicação entre os consumidores e as organizações, Mangold e Faulds (2009) estudaram métodos para que as empresas influenciem e moldem essa comunicação, de modo a alinhar a sua missão e os seus objetivos.

A identidade representa a extensão na qual os usuários das redes sociais digitais revelam sua identidade em um ambiente de mídia social, o que compreende a divulgação de várias informações, como nome, idade, sexo, profissão e local onde mora. Normalmente, a identidade é feita por meio da revelação que o internauta faz de suas informações pessoais, expostas consciente ou inconscientemente, como os pensamentos, os gostos, os desgostos e os sentimentos. Essas informações são expostas de acordo com a imagem que o usuário gostaria de passar (Kaplan; Haenlein, 2010).

Para que ocorra a interação cliente/empresa é necessário que exista uma razão para tal. Torna-se imprescindível que a empresa entenda e leve em consideração o que o seu cliente procura, o gostaria de ouvir, falar, o que acha interessante, agradável e valioso. Em seguida, é necessário que essas empresas desenvolvam e publiquem um conteúdo que se adapte a essas expectativas (Kaplan; Haenlein, 2010).

Uma conversação se configura na medida que ocorre a comunicação entre os usuários em uma mídia social. Muitas redes sociais digitais são criadas para facilitar a conversa entre indivíduos e grupos e essa pode acontecer por quaisquer razões. Atores sociais utilizam seus ambientes digitais para conhecer novos atores sociais, encontrar o amor verdadeiro, construir sua autoestima ou estarem abertos a novos questionamentos e tendências, enquanto outros podem entender esses ambientes como um veículo para apresentarem suas ideias e essas impactarem, positivamente, por exemplo, em causas humanitárias e nos problemas ambientais (Kietzmann et al., 2011).

Para os autores Kietzmann et al. (2011), o compartilhamento é um modo de interação nas plataformas de mídia social. A depender do objetivo da rede social digital em que estão inseridos, os usuários podem conversar entre si ou construir relacionamentos. De acordo com esses autores, existem, pelo menos, duas implicações fundamentais no caso de as empresas envolverem a mídia social na organização: a primeira é a de avaliar o que os objetos da sociedade e seus usuários têm em comum; e a segunda, identificar novos objetos que podem mediar seus interesses em comum. Sem esses objetos, uma rede social digital se constituirá, somente, de conexões entre atores sociais, sem um objetivo que os conecte mutuamente.

O engajamento dos consumidores aos canais digitais precisa ser trabalhado pelas empresas para que a mídia digital não seja considerada um mero desafio on-line. 0 novo modelo de negócios, chamado de marketing digital, é o resultado do aumento de oportunidades e da redução de custos que as empresas encontram nas propagandas tradicionais. A inovação e o conjunto de tecnologias trouxeram possibilidades às organizações de encontrarem as vertentes mercadológicas atuais e atingirem novas oportunidades (Camara, 2016).

0 relacionamento representa o grau de relação entre os usuários: as suas conversas, o compartilhamento de objetivos, encontros ou, simplesmente, serem amigos ou fãs. As plataformas de mídias sociais estão centradas na manutenção de relacionamentos já existentes e na construção de novos relacionamentos (Kietzmann et al., 2011).

Para Kietzmann et al. (2011), a reputação pode ter significados diferentes nas plataformas de mídia social. Ela pode ser a forma com que os usuários identificam a posição de outros usuários, ou representar uma questão de confiança. Na mídia social, reputação não é destinada somente aos atores sociais, mas também ao conteúdo. 
0 estudo de Schivinski e Dabrowski (2016) analisa a atitude dos consumidores acerca das marcas nas redes sociais digitais e constata que ela tem influência positiva tanto na imagem da empresa como na intenção de compra realizada pelos atores sociais. Nessa perspectiva, Lee e Hong (2016) afirmam que o conteúdo da informação e a criatividade também são essenciais para o sucesso dos anúncios presentes nas plataformas das redes sociais digitais.

Machado Mortari e Fernandes dos Santos (2016) constatam também que, por vezes, as redes sociais digitais podem ser extremamente úteis para gerenciamento de crises de imagem organizacional. A plataforma pode ser adequada para 0 monitoramento e a identificação de sinais de crises.

\section{PROCEDIMENTOS METODOLÓGICOS}

Sob a perspectiva da metodologia científica, classifica-se este trabalho como uma pesquisa básica (quanto à natureza do estudo), quantitativa (quanto à abordagem do problema) e exploratória (quanto ao objetivo).

A etapa qualitativa foi realizada com empresas da cidade de Blumenau, Santa Catarina, portanto, elas são a população desta pesquisa. 0 tipo de amostra selecionada foi o "não probabilístico intencional" que, de acordo com Mattar (2000), é uma amostra intencional na qual, com bom julgamento e uma tática adequada, pode-se selecionar casos a serem incluídos e chegar a amostras que sejam convincentes para as primordialidades da pesquisa.

A população foi selecionada conforme o critério "empresas de expressão" em sua categoria e possuíam um faturamento anual superior a 3 milhões de reais. Após o contato e a apresentação do objetivo desta pesquisa, de um total de onze empresas, sete aceitaram participar dos questionamentos em entrevista qualitativa. As sete participantes apresentam segmentos e faturamentos anuais distintos e são classificadas como:

Empresa 1 - segmento de varejo popular, com faturamento anual superior a 14 milhões de reais;

Empresa 2 - segmento de vendas de produtos hospitalares, com faturamento anual superior a 360 milhões de reais;

Empresa 3 - segmento de educação executiva, com faturamento anual superior a 10 milhões de reais;

Empresa 4 - segmento alimentício, com faturamento anual superior a 35 milhões de reais;

Empresa 5 - segmento de shopping centers, com faturamento anual superior a 55 milhões de reais;

Empresa 6 - segmento têxtil, com faturamento anual superior a 200 milhões de reais;

Empresa 7 - segmento automotivo, com faturamento anual superior a 3 milhões de reais.

Utilizou-se, como instrumento de coleta de dados, um roteiro de entrevistas elaborado a partir de uma adaptação do modelo teórico concebido por Kietzmann et al. (2011). Os autores definiram um quadro metodológico de categorização das plataformas de mídia social, com a utilização de sete blocos de construções funcionais: a presença, a identidade, as conversas, o relacionamento, o compartilhamento, os grupos e a reputação. Incluem-se, no roteiro, questões a respeito da presença do foco mobile nas ações desenvolvidas. 
A abordagem de coleta de dados adotada foi a entrevista pessoal, considerada uma conversa entre dois atores sociais, iniciada e dirigida pelo entrevistador. Essa abordagem tem como propósito obter informações relevantes para concretizar um estudo. As entrevistas foram feitas com os gestores de cada empresa e gravadas por um aplicativo de áudio. Ao final de cada uma, a gravação foi transcrita para uma tabela estruturada com cada um dos sete blocos funcionais.

No decorrer do estudo, as empresas entrevistadas foram identificadas por meio de números. A justificativa para essa conduta é a preservação do anonimato e da privacidade dos participantes no momento da coleta de dados de campo. Flick (2009) defende essa prática quando descreve que os dados de campo e as transcrições não devem conter informações concretas e reais sobre atores sociais, lugares e instituições. É importante que o entrevistador garanta a confidencialidade e assegure aos participantes que as suas informações serão usadas somente com autorização.

Para a análise, utilizou-se a técnica de triangulação de dados, definida, por Flick (2009), como uma coleta de dados realizada a partir de diferentes perspectivas acerca de um estudo. Essas podem ser alcançadas por diferentes procedimentos e abordagens teóricas, e ambos precisam estar correlacionados. Nas palavras de Flick (2009, p. 62), "a triangulação deve produzir conhecimento em diferentes níveis, o que significa que eles vão além daquele possibilitado por uma abordagem". A triangulação necessita efetivar a ligação entre os métodos adotados, bem como fazer com que as perspectivas teóricas se vinculem a eles. Esse método contribui com a qualidade da pesquisa.

\section{APRESENTAÇÃO E DISCUSSÃO DOS RESULTADOS}

Por meio da pesquisa de campo, foi possível verificar que as empresas 2, 3 e 5 são as que mais praticam as estratégias estudadas pelos autores citados. Em contrapartida, a empresa 6 é a que menos pratica. Por se considerar relevante o "mobile" para as empresas, foi ativado o tópico "Mobile" no bloco "Presença", por se presumir a necessidade de as marcas estarem integradas a esse meio.

A estratégia de "Comunidades" foi incluída no bloco "Compartilhamento", pois os autores Kietzmann et al. (2011) descrevem, dentro desse bloco, que as empresas interessadas em se envolver na mídia social precisam avaliar o que os usuários possuem em comum e identificar o que pode mediar esses interesses partilhados. Em compensação, os autores Mangold e Faulds (2009) defendem que os usuários gostam de interagir com atores sociais que possuem interesses e desejos similares aos seus. Por essa razão, as organizações precisam criar comunidades para consumidores com a mesma opinião, a fim de influenciarem e mediarem esse desejo em comum.

As estratégias do bloco "Presença" são praticadas pela maioria das empresas que estão inseridas em pelo menos uma rede social digital, e um grande número dessas empresas, com exceção da empresa 6, possui disponibilidade de atendimento ao cliente. Essa disponibilidade oscila de acordo com as estratégias de cada organização e pode ser de 30 minutos, 2 horas ou no mesmo período - manhã, tarde ou noite. A importância de estar inserido nas redes sociais digitais e de oferecer disponibilidade de atendimento ao cliente são estudadas pelos autores Yanaze (2011), Kietzmann et al. (2011), Zhu e Chen (2015), Pinhanez (2015), Silva, Alves e Oliveira (2016) e Wang e Kim (2017).

Apesar da importância, a maioria das empresas não faz investimento no mobile e não possui estratégias específicas para isso. Por outro lado, todas elas estão inseridas no mobile automaticamente, visto que as plataformas de redes sociais digitais são adaptadas para o meio. Outrossim, a maioria das empresas possui um site responsivo - adaptado para o mobile - e as empresas 2 e 5 já investiram em um aplicativo. 
No bloco "Identidade", percebe-se que o principal objetivo das empresas entrevistadas, no que se refere às redes sociais digitais, é o foco na marca, seguido do objetivo de estreitar o relacionamento com o cliente. Todos os gestores afirmaram que é perceptível o surgimento de novas oportunidades com a utilização das plataformas de mídia social, o que vem ao encontro da opinião de Pinhanez (2015). Ele descreve que é possível as empresas encontrarem novas oportunidades e negócios por meio do comportamento e das informações que os usuários disponibilizam nas redes sociais digitais.

Já no bloco "Conversas" é visto que os conteúdos das redes sociais digitais dessas empresas são criados por uma agência de comunicação ou pela própria empresa, por meio de um profissional especializado em mídia social ou, como acontece na empresa 2, de uma agência de comunicação constituída e inserida na própria empresa. As empresas 1, 2, 3, 5 e 7 publicam 0 mesmo conteúdo em todas as redes sociais digitais e as empresas 2, 4 e 5 sabem quais conteúdos são os mais relevantes e procuram repeti-los. Com relação a ter um feedback do cliente, defendido como importante por Mangold e Faulds (2009) e por Hanna, Rohm e Crittenden (2011), somente as empresas 2, 3 e 5 possuem essa estratégia e mesmo assim não é realizado por meio das redes sociais digitais.

A criação de comunidades, elaboradas de acordo com a preferência de seu público, já constituiu uma estratégia da empresa 2, a qual obteve muito sucesso com esse procedimento. Tal estratégia é defendida por Mangold e Faulds (2009), que também evidenciam a importância da identificação, por parte das empresas, do que os consumidores possuem em comum. As empresas 2, 3 e 4 relataram que sabem identificar e utilizam essa informação para a criação de conteúdos para as redes sociais digitais. Em relação ao incentivo dado aos clientes para publicarem fotos de produtos e serviços adquiridos na empresa, a maioria dos gestores responderam que não possuem esse costume, o que impossibilita a criação de uma propaganda espontânea para a empresa.

No bloco "Grupos", a principal estratégia relatada é a de incentivar os consumidores a abraçar as causas sociais. Os gestores das empresas 1, 2, 3, 5 e 7 comunicaram que se utilizam dessa prática e, além de incentivarem seus consumidores, buscam também abraçar as causas sociais para que sirva de exemplo ao seu público-alvo.

A maioria dos gestores entrevistados classifica como "boa" a reputação de sua empresa nas redes sociais digitais. Todavia, somente a empresa 2 possui uma ferramenta analítica para avaliar tal questão. As empresas 3, 4 e 7 fazem uma análise superficial para chegar a esse resultado. Por outro lado, a empresa 1 classifica sua reputação como boa, baseada na análise de relevância e afinidade que seu público-alvo tem com a página da empresa no Facebook. Somente as empresas 2 e 5 monitoram o quanto o nome da organização é mencionado nas redes sociais digitais e procuram agradecer na medida que respondem a essas menções.

Apesar de todas as empresas estarem presentes nas redes sociais digitais e buscarem estratégias que tragam resultados a sua organização, a maioria delas alegou o desconhecimento do que pode ser mais eficiente e correto na utilização dessas plataformas de mídia social. Algumas empresas relataram que existe um déficit, por parte das agências de comunicação, quanto à orientação e à explicação da maneira correta de se trabalhar para se obter uma melhor estratégia no uso das redes sociais digitais.

Mesmo que essas plataformas permitam tentativas de erros e acertos, é importante conhecê-las e saber usá-las em benefício dos objetivos da organização. É importante que os profissionais responsáveis pela comunicação da marca busquem o aperfeiçoamento e o conhecimento desse meio e, sobretudo, que procurem se destacar e aproveitar as vantagens e os retornos que as diferentes plataformas de mídia social proporcionam para quem investe nelas.

Na Figura 1, é possível compreender os principais tópicos que compõem cada bloco funcional, bem como as respectivas empresas que têm esses tópicos em suas estratégias de mídia social. 
Figura 1: Análise Blocos de Construções Funcionais.

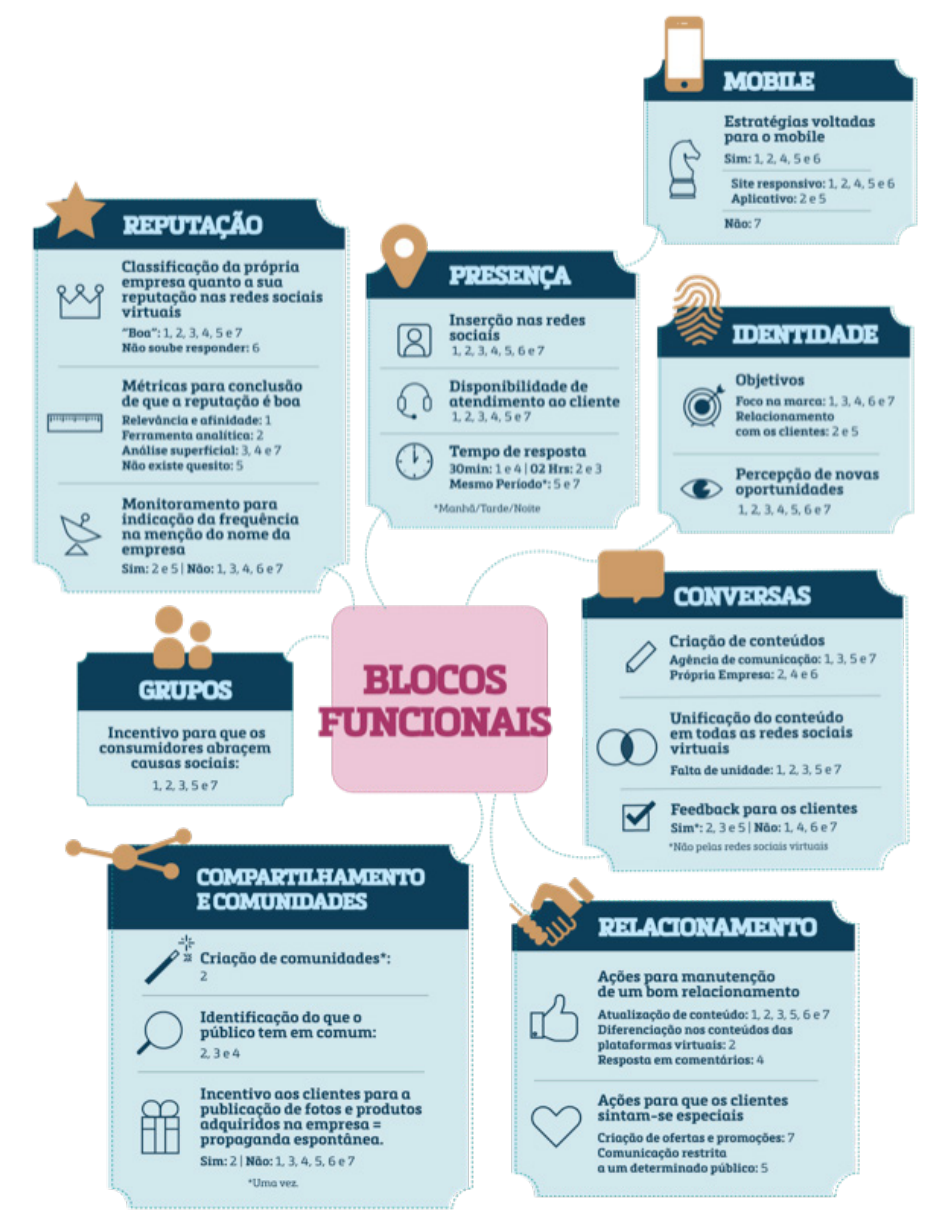

Fonte: elaborado pelos autores a partir da pesquisa, 2016.

\section{CONSIDERAÇÕES FINAIS}

O novo modelo de comunicação, implantado com o advento da internet, possibilitou a interação entre uma marca e seus consumidores e forçou, de certo modo, a participação das empresas no mundo on-line. As plataformas da mídia social permitem que o público esteja mais perto de uma organização e influencie, vigorosamente, o seu modo de comunicação. A importância de uma empresa estar inserida nas redes sociais digitais está, diretamente, relacionada aos novos modos de aumentar o desempenho do seu negócio, criar recursos e sustentar o próprio sucesso.

Saber se colocar e traçar estratégias nas redes sociais digitais tornam-se um desafio para as organizações, principalmente pelas redes sociais se constituírem em uma nova ferramenta de publicidade da marca e em um novo canal de troca de informações entre consumidor e empresa. 0 conhecimento da maneira correta, de como fazer e de como agir ainda é pouco. Os gestores possuem uma grande carência de informações sobre esse assunto, o que afeta diretamente suas atitudes dentro da empresa. Por essa razão, ainda existem muitos questionamentos a serem respondidos: qual a maneira correta de proceder e quais são as ações que mais trazem retorno à marca.

A possibilidade de analisar a gestão da comunicação sob a ótica dos gestores apresenta uma perspectiva de levantamento de dados que vai além do monitoramento das atitudes do consumidor, comumente evidenciado na literatura atual.

Este estudo teve por objetivo a análise das estratégias de utilização das redes sociais digitais das empresas de Blumenau, a partir da teoria dos Blocos de Construções Funcionais. Por meio da coleta de dados, notou-se que algumas empresas possuem um conhecimento muito primário e precário de comunicação digital, principalmente com referência às redes sociais digitais. Elas tendem a buscar o apoio de suas agências de comunicação para se comportarem adequadamente nessas plataformas. 
Apesar do conhecimento de suas limitações, todas entendem a importância de estarem inseridas nesse meio e a maioria delas busca melhorar as suas estratégias para atrair mais clientes. As empresas que não investem tempo e dinheiro nas redes sociais digitais são aquelas que possuem, em suas estratégias, um investimento com retorno de curto prazo.

Todavia, existem aquelas empresas que se esforçam no aperfeiçoamento de sua comunicação nas redes sociais digitais, visto que essas plataformas acabam por substituir, muitas vezes, o lugar da mídia tradicional. No entanto, as empresas alvo desta pesquisa tratam as redes sociais digitais de maneira integrada com as demais plataformas de mídia. Elas não deixam de investir na mídia tradicional e procuram realizar uma comunicação conjunta. Esse comportamento pode ser constatado na definição das estratégias e da verba que são pensadas como um todo e não de modo individualizado. Busca-se uma comunicação unificada que explore os diferenciais de cada mídia e estimule seu potencial de crescimento.

As análises empreendidas neste trabalho evidenciaram a importância das redes sociais digitais para as empresas, bem como os seus mais diversos benefícios. Um desses é a oportunidade de ter mais de um canal de relacionamento com os clientes; é necessário que os consumidores localizem a marca onde estiverem e no momento que precisarem. As redes sociais digitais facilitam essas questões. Ademais, essas plataformas permitem que a empresa exponha os seus produtos e serviços e elabore ações promocionais voltadas para esse meio. Dentre os variados benefícios, salienta-se o baixo investimento necessário, 0 que torna uma mídia barata, de fácil acesso e de grande alcance.

Constatou-se também que existem dois objetivos principais das empresas dentro das redes sociais digitais: o primeiro é utilizar essa plataforma como um meio de divulgação da marca na intenção de atrair novos clientes e de fidelizar os atuais; o outro é estreitar e melhorar o relacionamento com o cliente. As empresas relataram que as suas redes sociais digitais se transformaram em um canal de Serviço de Atendimento ao Cliente (SAC), o que garante uma comunicação mais rápida, objetiva e fácil entre a empresa e o cliente. Independentemente do objetivo que uma empresa possua em relação à mídia digital, é de grande importância que ela faça parte desse meio e que o torne acessível aos seus clientes.

Soma-se, a tudo o que foi mencionado, a percepção de novas oportunidades e negócios para as empresas com a utilização das redes sociais digitais, visto que essas plataformas fornecem muitos benefícios e resultados para seus usuários. Convém destacar que só a utilização das redes sociais digitais não trará resultados significativos para a empresa; é necessário trabalhá-la em conjunto com todos os pilares da organização e torná-la parte do mix de comunicação de uma marca. Contudo, apesar das redes sociais digitais permitirem tentativas, faz-se necessário traçar objetivos e criar estratégias que busquem um retorno satisfatório do investimento e do trabalho que são gerados nessas plataformas.

Metodologicamente, os conceitos base deste estudo estão baseados na obra de Kietzmann et al. (2011), que definiram um quadro metodológico de categorização das plataformas de mídia social com a utilização dos sete blocos de construções funcionais mencionados. Incluiu-se, no roteiro, questões a respeito da presença do foco mobile nas ações desenvolvidas. Os resultados contribuem para a literatura ao mostrar que, apesar de amplamente difundida e consolidada, a gestão da comunicação das redes sociais digitais não está centrada na área estratégica das organizações, principalmente as de grande porte.

As limitações deste estudo estão nas restrições da amostra, uma vez que algumas empresas se recusaram a participar das entrevistas. Alegaram que não poderiam revelar suas estratégias ou que não possuíam estratégias definidas para esse meio e, portanto, não tinham interesse em contribuir com o estudo.

Para estudos futuros, sugere-se entrevistar também os consumidores das empresas participantes, para permitir o cruzamento de dados e a veracidade de informações. Essas entrevistas poderão auxiliar as organizações quanto ao seu comportamento nas redes sociais digitais, bem como ajudar na elaboração de novos objetivos e estratégias que trarão um retorno mais 
significativo para os investimentos realizados. Ademais, possibilitarão resultados comprovados das percepções que cada gestor possui acerca da atuação de sua marca nessas plataformas de mídia social.

\section{REFERÊNCIAS}

BAREFOOT, Darren; SZABO, Julie. Manual de marketing em mídias sociais. São Paulo: Novatec Editora, 2010.

CAMARA, Eduardo. Companhias necessitam engajar os consumidores nos canais digitais e isso é uma questão muito maior do que um simples desafio digital. Innovation Insider, São Paulo, 2016. Disponível em: <goo.gl/J42RXz>. Acesso em: 2 maio 2016.

CASTRONOVO, Cristina; HUANG, Lei. Social media in an alternative marketing communication model. Journal of Marketing Development and Competitiveness, West Palm Beach, v. 6, n.1, p. 117-131, 2012.

DIMITRIADIS, Sergios; TSIMONIS, Georgios. Brand strategies in social media. Marketing Intelligence \& Planning, Bingley, v. 32, n. 3, p. 328-344, 2014. Disponível em: <http://dx.doi.org/10.1108/MIP-04-2013-0056>. Acesso em: 2 maio 2017.

FLICK, Uwe. Desenho da pesquisa qualitativa. Porto Alegre: Artmed, 2009.

GLOBALWEBINDEX.GWI Market Report Brazil. Londres, 2016. Disponível em: <https://goo.gl/eH8Eop>. Acesso em: 17 abr. 2017.

HANNA, Richard; ROHM, Andrew; CRITTENDEN, Victoria Lynn. We're all connected: the power of the social media ecosystem. Business Horizons, Bloomington, v. 54, p. 265-273, 2011.

INSTITUTO BRASILEIRO DE GEOGRAFIA E ESTATÍSTICA - IBGE. Santa Catarina: Blumenau. 2016. Disponível em: <https://goo. gl/A4qVs7>. Acesso em: 25 maio 2016.

INSTITUTO BRASILEIRO DE OPINIÃO PÚBLICA E ESTATÍSTICA - IBOPE. Pesquisa Brasileira de Mídia - 2016. Disponível em: <goo.gl/Zc7X6R>. Acesso em: 12 out. 2017.

JENKINS, Henry. Convergência e conexão são o que impulsiona a mídia agora. Entrevista concedida a Priscila Kalinke e Anderson Rocha. Intercom: Revista Brasileira de Ciências da Comunicação, São Paulo, v. 39, n. 1, p. 213-219, jan./abr. 2016.

JUE, Arthur L.; MARR, Jackie Alcalde; KASSOTAKIS, Mary Ellen. As mídias sociais nas empresas: colaboração, inovação, competitividade e resultados. São Paulo: Évora, 2010.

KAPLAN, Andreas; HAENLEIN, Michael. Users of the world, unite: the challenges and opportunities of social media. Business Horizons, Bloomington, v. 53, p. 59-68, 2010.

KIETZMANN, Jan et al. Social media? Get serious! Understanding the functional building blocks of social media. Business Horizons, Bloomington, v. 54, p. 241-251, 2011.

LEE, Jieun; HONG, Ilyoo B. Predicting positive user responses to social media advertising: the roles of emotional appeal, informativeness, and creativity. International Journal of Information Management, Amsterdam, v. 36, n. 3, p.360-373, 2016. 
LIMEIRA, Tania M. Vidigal. E-marketing: o marketing na internet com casos brasileiros. São Paulo: Saraiva, 2007.

MANGOLD, W. Glynn; FAULDS, David J. Social media: the new hybrid element of the promotion mix. Business Horizons, Bloomington, v. 52, p. 357-365, 2009.

MATTAR, Fauze Najib. Pesquisa de marketing. 2. ed. São Paulo: Atlas, 2000.

MENDONÇA, Marcus Mentzingen de. As redes sociais virtuais: motivos para a utilização pelas organizações no Brasil. 2013. Dissertação (Mestrado Profissional em Gestão Empresarial) - Escola Brasileira de Administração Pública e de Empresas, Rio de Janeiro, 2013.

MORTARI, Elisangela Carlosso Machado; SANTOS, Suzana Fernandes dos. Monitoramento de redes sociais digitais como estratégia organizacional.Intercom: Revista Brasileira de Ciências da Comunicação, São Paulo, v. 39, n. 1, p. 91-109, 2016.

OKAZAKI, Shintaro; TAYLOR, Charles R. Social media and international advertising: theoretical challenges and future directions. International Marketing Review, v. 30, n. 1, p. 56-71, 2013. Doi: 10.1108/02651331311298573.

PINHANEZ, Claudio. As redes sociais falam; os bancos vendem serviços. Innovation Insider, São Paulo, 2015. Disponível em: $<$ https://goo.gl/efkZBu>. Acesso em: 4 maio 2016.

RODGERS, Shelly; THORSON, Esther. The interactive advertising model: how users perceive and process online ads. Journal of Interactive Advertising, Abingdon, v. 1, n. 1, p. 42-61, 2010.

SCHIVINSKI, Bruno; DABROWSKI, Dariusz. The effect of social-media communication on consumer perceptions of brands. Journal of Marketing Communications, Abingdon, v. 22, n. 2, p. 189-214, 2016.

SILVA, Fábio Braun; ALVES, Matheus de Arruda Rodrigues; OLIVEIRA, Paulo Roberto Miranda de. Práticas empreendedoras: uma análise das redes sociais como forma de impulsionar a gestão de vendas e os negócios das empresas. Revista Conbrad, Maringá, v. 1, n. 1, p. 177-190, 2016.

SOUSA, Daniel. A transição do trade marketing tradicional para o digital. Innovation Insider, São Paulo, 2016. Disponível em: <https://goo.gl/QR2wN3>. Acesso em: 4 maio 2016.

WANG, Zhan; KIM, Hyun Gon. Can social media marketing improve customer relationship capabilities and firm performance? Dynamic capability perspective. Journal of Interactive Marketing, New York, v. 39, p. 15-26, 2017.

YANAZE, Mitsuru Higuchi. Gestão de marketing e comunicação: avanços e aplicações. 2. ed. São Paulo: Saraiva, 2011.

ZHU, Yu-Qian; CHEN, Houn-Gee. Social media and human need satisfaction: Implications for social media marketing. Business Horizons, Bloomington, v. 58, p. 335-345, 2015.

Texto recebido em 26.05.2017 e aprovado em 22.09.2017. 